\title{
Lisina em Rações para Fêmeas Suínas Primíparas em Lactação
}

\section{Fabienne Petitinga de Paiva ${ }^{2}$, Juarez Lopes Donzele ${ }^{3}$, Rita Flávia Miranda de Oliveira ${ }^{3}$, Márvio Lobão Teixeira de Abreu ${ }^{4}$, Lourdes Romão Apolônio ${ }^{5}$, Ciro Alexandre Alves Torres ${ }^{3}$, Antônio Marcos Souto Moita6}

\begin{abstract}
RESUMO - Foram utilizadas 50 fêmeas primíparas de linhagem comercial, com peso de 210,3 $\pm 22,5 \mathrm{~kg}$, para avaliar diferentes níveis de lisina total $(0,95 ; 1,03 ; 1,10 ; 1,18 ;$ e $1,25 \%)$ na ração, durante um período de lactação de $17,69 \pm 1,17$ dias. Utilizou-se o delineamento experimental de blocos ao acaso, com cinco tratamentos e dez repetições, considerando-se cada matriz a unidade experimental. O consumo total de ração não variou entre os animais dos tratamentos, sendo que as porcas consumiram em média $4,3 \mathrm{~kg}$ de ração por dia. $\mathrm{O}$ consumo de lisina aumentou de forma linear. Não se observou efeito dos tratamentos sobre os parâmetros produtivos e reprodutivos das matrizes em lactação. O ganho de peso dos leitões também não foi influenciado pelo consumo de lisina das fêmeas em lactação. Concluiu-se que porcas primíparas em lactação exigem $0,95 \%$ de lisina total na ração, correspondente a um consumo diário de 40,47 g de lisina total.
\end{abstract}

Palavras-chave: leitões, matrizes primíparas, reprodução, lisina, lactação

\section{Lysine in the Diet of Primiparous Lactating Sows}

ABSTRACT - Fifty crossbred primiparous sows averaging weight of $210.3 \pm 22.5 \mathrm{~kg}$ were used to evaluate the total lysine levels $(0.95,1.03,1.10,1.18$ and $1.25 \%)$ in the diet, during lactation (17.69 \pm 1.17 days). A randomized blocks design with five treatments and ten replicates the sow as the experimental unit was used. During the experimental period, the sows were daily fed $4.3 \mathrm{~kg}$ of diet. Lysine intake increased linearly, in response to the dietary lysine levels. The productive and reproductive parameters of the sows were not influenced by the dietary lysine levels. Piglet weight gain did not change with the sow lysine intake. It was concluded that the total lysine level correspondent to a daily intake of $40.47 \mathrm{~g}$ met the lysine requirements of lactating primiparous sows.

Key Words: litter, primiparous sows, reproduction, lysine, lactation

\section{Introdução}

A produtividade de uma granja de suínos pode ser avaliada pela sua eficiência reprodutiva, representada pelo número leitões terminados por matriz ao ano, que, por sua vez, é influenciado pelo número de leitões nascidos vivos por parto e pelo número de partos por fêmea ao ano. O desempenho das matrizes, entretanto, é dependente de fatores, como genética, manejo, ambiente e nutrição, que influenciam diretamente a produtividade da empresa suinícola.

Entre as categorias de fêmeas, as matrizes de primeiro parto são as que mais sofrem durante $o$ período de lactação, por apresentarem consumo de alimento insuficiente, em razão da menor capacidade gastrointestinal para atender à demanda da produção láctea e ao desenvolvimento corporal. É importante aprofundar os conhecimentos sobre as necessidades nutricionais desses animais, sobretudo a exigência nutricional de lisina, considerada o primeiro aminoácido limitante para a espécie suína, sendo utilizada como referência para o estabelecimento das exigências de outros aminoácidos essenciais, segundo o conceito de proteína ideal. Além disso, o consumo de lisina na lactação pode influenciar variáveis importantes, como o ganho de peso dos leitões durante esse período e o desempenho reprodutivo subseqüente, representado pelo intervalo desmamaestro e pelo tamanho da leitegada no segundo parto (Touchette et al., 1998)

Diversos estudos têm demonstrado que a baixa ingestão de lisina durante a lactação pode acarretar redução do ganho de peso da leitegada (King \& Dunkin, 1986; Richert et al., 1994; Jones \& Stahly, 1999a; Yang et al., 2000b) e do número de leitões nascidos no segundo parto (Touchette et al., 1998).

\footnotetext{
${ }^{1}$ Parte do trabalho de tese de D.S. da primeira autora.

2 Médica Veterinária, Fundação Oswaldo Cruz. E.mail: fabienne@cpqgm.fiocruz.br

3 Professor (a) do DZO/UFV. E.mail: donzele@ufv.br; flavia@ufv.br;ctorres@ufv.br

4 Professor do DZO/UFPI. Estudante de Doutorado da UFV. E.mail: marvioabreu@tdnet.com.br

${ }^{5}$ Estudante de Doutorado da UFV.E.mail: Irapolonio@hotmail.com

${ }^{6}$ Zootecnista, Nutricionista da Agroceres.
} 
Fêmeas primíparas com baixa ingestão de lisina, mesmo quando associada a altos níveis de energia durante a lactação, podem retornar ao estro mais tarde, reduzindo, conseqüentemente, sua eficiência reprodutiva (Jones \& Stahly, 1999b; Tokach et al., 1992). A queda do desempenho reprodutivo pode estar relacionada à maior mobilização de nutrientes corporais e à conseqüente perda de peso das matrizes durante a lactação. De acordo com Richert et al. (1994) e Yang et al. (2000b), fêmeas primíparas que consomem baixas quantidades de lisina apresentam maior perda de peso ao final da lactação. Por outro lado, segundo Wilson et al. (1996), a utilização de lisina em níveis acima dos recomendados para o máximo crescimento dos leitões (entre 50 e 60 g/dia) reduz o intervalo desmama-estro de fêmeas primíparas e eleva sua produtividade.

Os trabalhos publicados nos últimos anos (Knabe et al., 1996; Jones e Stahly, 1999 a,b) sobre a nutrição da matriz suína indicam a necessidade de atualização de suas exigências nutricionais. Muitos programas nutricionais ainda se baseiam em resultados obtidos em pesquisas com reprodutoras que se diferenciam das atuais quanto às capacidades de crescimento, de ingestão de alimento, de reservas corporais e de produção de leite e de leitões. Além disso, para maximizar a vida útil da matriz, ao estabelecer um programa nutricional, a preocupação não deve ser somente com o crescimento da leitegada, mas também com o desempenho reprodutivo futuro da matriz.

Conduziu-se este estudo para determinar o melhor nível de lisina em rações para matrizes suínas primíparas em lactação, considerando-se os desempenhos produtivo e reprodutivo da matriz e o desempenho da leitegada.

\section{Material e Métodos}

O experimento foi conduzido nas instalações da Granja Paraíso, localizada no município de Patos de Minas, Minas Gerais, pertencente à empresa Agroceres Nutrição Animal, no período de junho a julho de 2002.

Foram utilizadas 50 fêmeas primíparas de linhagem comercial, com peso inicial pós-parto de $210,3 \pm 22,5 \mathrm{~kg}$. $\mathrm{O}$ delineamento experimental foi o de blocos ao acaso, com cinco tratamentos $(0,95 ; 1,03 ; 1,10 ; 1,18$; e $1,25 \%$ de lisina total na ração) e dez repetições, considerando-se cada matriz uma unidade experimental.
As matrizes foram distribuídas nos tratamentos de acordo com o peso inicial e a espessura de toucinho e, durante a fase de gestação, receberam o mesmo manejo alimentar, ou seja: da cobertura ao sétimo dia de gestação: $1,70 \mathrm{~kg} /$ dia; do $8^{\circ}$ ao $30^{\circ}$ dia: $2,0 \mathrm{~kg} / \mathrm{dia}$; e do $31^{\circ}$ ao $60^{\circ}$ dia: $2,50 \mathrm{~kg} /$ dia de uma ração contendo $2.850 \mathrm{kcal} / \mathrm{kg}$ de EM, $14 \% \mathrm{~PB}$ e $0,68 \%$ de lisina total. Do $61^{\circ}$ ao $85^{\circ}$ dia de gestação, as matrizes receberam ração na proporção de $2,5 \mathrm{~kg} /$ dia e, do $86^{\circ}$ até o dia da transferência para a maternidade, $3,3 \mathrm{~kg} /$ dia de uma ração contendo $3.150 \mathrm{kcal} / \mathrm{kg}$ de EM, $17 \%$ de PB e $0,90 \%$ de lisina total.

Entre o $107^{\circ}$ e o $110^{\circ}$ dia de gestação, as marrãs foram transferidas do galpão de gestação para a sala de maternidade, onde permaneceram alojadas individualmente, em gaiolas metálicas com 2,20 m de comprimento x 1,40 m de largura, providas de comedouro tipo cocho, bebedouro automático tipo concha e campânulas para aquecimento da leitegada.

A temperatura no interior das salas de maternidade foi monitorada diariamente durante todo o período experimental, por meio de termômetros de máxima (TMX) e mínima (TMN), de bulbos seco (TBS) e úmido (TBU) e de globo negro (TGN), mantidos no centro dos galpões, à altura aproximada à do corpo dos animais.

As composições centesimal e calculada das rações experimentais encontram-se na Tabela 1. As rações experimentais, à base de milho e farelo de soja, foram formuladas para atenderem às exigências de proteína bruta, conforme recomendações do NRC (1998) para fêmeas com 10 leitões, com ganho de peso médio da leitegada de $2.000 \mathrm{~g} / \mathrm{dia}$. Os níveis de lisina foram obtidos por meio da suplementação com L-Lisina-HCl, em substituição ao caulim (inerte).

Para assegurar que a lisina fosse o primeiro aminoácido limitante nas rações, os demais aminoácidos foram mantidos em um nível mínimo correspondente a $105 \%$ da relação com a lisina, conforme proposto pelo NRC (1998), com exceção dos aminoácidos valina e triptofano, cujas relações com a lisina corresponderam a 89 e $20 \%$, respectivamente, conforme proposto por Carter et al. (2000). As exigências de cálcio e fósforo foram estimadas segundo recomendações de Rostagno et al. (2000).

As rações experimentais foram fornecidas em quantidade fixa de $4,5 \mathrm{~kg} / \mathrm{animal} / \mathrm{dia}$, estimulando-se o consumo quatro vezes ao dia, para assegurar um consumo de lisina total de 42,$75 ; 46,35 ; 49,50 ; 53,10$; 
e 56,25 g/dia, correspondentes, respectivamente, aos níveis de 0,$95 ; 1,03 ; 1,10 ; 1,18$ e $1,25 \%$ de lisina total (tratamentos). $\mathrm{O}$ acesso à água foi à vontade.

As matrizes foram pesadas até 24 horas após o parto e suas espessuras de toucinho (ET) foram mensuradas no momento da pesagem, por meio de ultra-som, efetuando-se duas medidas, $6,5 \mathrm{~cm}$ à direita e à esquerda da linha dorsal do animal, à altura da $10^{\mathrm{a}}$ costela (ponto $\mathrm{P} 2$ ), tomando-se como resultado a média das avaliações obtidas nos dois lados. No dia do desmame, as marrãs foram novamente pesadas e a espessura de toucinho mensurada.

As leitegadas foram padronizadas em 9 ou 10 leitões até o segundo dia após o parto. Os leitões receberam manejo tradicional para a categoria (corte de dentes e de cauda, cura do umbigo, marcação e administração de antibiótico até 24 horas após o nascimento e aplicação de ferro dextrano no terceiro dia). Durante a lactação, os leitões não tiveram acesso à ração, porém, receberam água à vontade em bebedouros do tipo chupeta. Os leitões foram pesados até 24 horas após o nascimento e na ocasião do desmame.

Após o desmame, realizado aos 17,69 $\pm 1,17$ dias, as fêmeas foram levadas para galpões de gestação, alojadas em baias individuais e passaram a receber, à vontade, uma ração contendo $3.400 \mathrm{kcal} / \mathrm{kg}$ de EM, $18 \%$ de $\mathrm{PB}$ e $1,2 \%$ de lisina total. A verificação do

Tabela 1 - Composições percentual e calculada das rações experimentais

Table 1 - Ingredient composition (\%) of the experimental diets

\begin{tabular}{|c|c|c|c|c|c|}
\hline \multirow[t]{2}{*}{$\begin{array}{l}\text { Ingrediente (\%) } \\
\text { Ingredient }\end{array}$} & \multicolumn{5}{|c|}{$\begin{array}{c}\text { Nível de lisina total na ração }(\%) \\
\text { Total lysine level in the diets }\end{array}$} \\
\hline & 0,95 & 1,03 & 1,10 & 1,18 & 1,25 \\
\hline Farelo de soja (Soybean meal) & 27,510 & 27,510 & 27,510 & 27,510 & 27,510 \\
\hline Calcário calcítico (Limestone) & 0,635 & 0,635 & 0,635 & 0,635 & 0,635 \\
\hline Fosfato bicálcico (Dicalcium phosphate) & 2,520 & 2,520 & 2,520 & 2,520 & 2,520 \\
\hline L-treonina (L-threonine) & 0,000 & 0,019 & 0,071 & 0,122 & 0,174 \\
\hline L-triptofano (L-thryptophan) & 0,000 & 0,000 & 0,007 & 0,023 & 0,037 \\
\hline L-valina (L-valine) & 0,000 & 0,000 & 0,070 & 0,136 & 0,202 \\
\hline Inerte (Caulim) & 0,925 & 0,811 & 0,572 & 0,301 & 0,032 \\
\hline Óleo vegetal (Vegetable oil) & 6,740 & 6,740 & 6,740 & 6,740 & 6,740 \\
\hline TOTAL & 100,000 & 100,000 & 100,000 & 100,000 & 100,000 \\
\hline \multicolumn{6}{|l|}{ Composição calculada } \\
\hline \multicolumn{6}{|l|}{ Calculated composition } \\
\hline Energia digestível (Digestible energy)(kcal/kg) & 3.600 & 3.600 & 3.600 & 3.600 & 3.600 \\
\hline Proteína bruta (Crude protein) $(\%)$ & 17,20 & 17,20 & 17,20 & 17,20 & 17,20 \\
\hline Lisina total (Total lysine) $(\%)$ & 0,95 & 1,03 & 1,10 & 1,18 & 1,25 \\
\hline Lisina digestível (Digestible lysine) (\%) & 0,84 & 0,91 & 0,99 & 1,06 & 1,14 \\
\hline Metionina + cistina digestível (Digestible Methionine + Cystine) $(\%)$ & 0,529 & 0,529 & 0,543 & 0,585 & 0,626 \\
\hline Treonina digestível (Digestible threonine) $(\%)$ & 0,602 & 0,621 & 0,672 & 0,722 & 0,773 \\
\hline Triptofano digestível (Digestible thryptophan) (\%) & 0,191 & 0,191 & 0,198 & 0,213 & 0,227 \\
\hline Valina digestível (Digestible valine) (\%) & 0,810 & 0810 & 0,880 & 0,946 & 1,011 \\
\hline
\end{tabular}

${ }^{1}$ Composição por kg do produto (Composition by kg of product): Fe, 180 g; Cu, 20 g; Co, 4 g; Mn, 80 g; Zn, 140 g; 1,4 g e excipiente (vehicle) q.s.p., $1.000 \mathrm{~g}$.

2 Composição por kg do produto (Composition by kg of product): vit. A, 12.000 .000 UI; vit. D3, 1.500 .000 UI; vit. E, 8.000 UI; vit. K3, 4 g; vit. B2, 4 g; vit. B6, 5 g; vit. B12, 30.000 mg; ácido nicotínico (nicotinic acid), 40 g; ácido pantotênico (pantothenic acid), 20 g; bacitracina de zinco (zinc bacitracin), $10 \mathrm{~g}$; antioxidante (antioxidant), $30 \mathrm{~g}$; selênio (selenium), $23 \mathrm{mg}$; e excipiente (vehicle) q. s. p. $1.000 \mathrm{~g}$.

${ }^{3}$ Butil hidroxi toluene $99 \%$. 
início do estro foi feita todos os dias, pela manhã e à tarde, levando-se o cachaço às gaiolas das fêmeas. Foram consideradas em estro as fêmeas que permaneceram imóveis à monta (reflexo de tolerância ao macho, RTM - positivo). O parto subseqüente das matrizes foi acompanhado, para avaliação do número de leitões nascidos vivos.

As variáveis de desempenho das matrizes e das leitegadas foram submetidas à análise de variância utilizando-se o programa computacional Sistema de Análises Estatísticas e Genéticas - SAEG (UFV, 1997). As estimativas da exigência de lisina digestível foram realizadas com base nos resultados obtidos, adotando-se os modelos de regressão linear e quadrático.

Para as análises de ganho de peso e de peso ao desmame dos leitões e da leitegada, foram utilizadas como covariáveis, respectivamente, o peso dos leitões ao nascer e o peso da leitegada ao nascimento. Para a análise de variação de peso, adotou-se como covariável o peso da fêmea ao parto.

\section{Resultados e Discussão}

As temperaturas na sala de maternidade durante o período experimental, obtidas por meio dos termômetros de máxima (TMX), de mínima (TMN), de bulbos seco (TBS) e úmido (TBU) e de globo negro (TGN), são apresentadas na Tabela 2.

Uma vez que a faixa de conforto térmico das matrizes situa-se entre 12 e $25^{\circ} \mathrm{C}$ (Nääs, 2000), pode-se inferir, com base nas temperaturas registradas durante o período experimental (de 16 a $33,5^{\circ} \mathrm{C}$ ), que as matrizes foram expostas a períodos de temperatura ambiental acima da faixa de conforto, o que pode ter influenciado seu padrão de resposta.

Os resultados dos consumos diários de ração, de lisina total e de energia encontram-se na Tabela 3. O consumo médio diário de ração das matrizes não foi influenciado $(\mathrm{P}>0,05)$ pelos tratamentos, de modo que o valor médio de consumo $(4,26 \mathrm{~kg})$ foi inferior ao consumo pré-determinado (4,5 kg/matriz). Tokach et al. (1992) e Cota et al. (2003), avaliando níveis de lisina para marrãs em lactação, também verificaram que os animais não alcançaram o consumo de ração pré-estabelecido.

Os períodos de alta temperatura aos quais os animais foram expostos durante o experimento, conforme relatado anteriormente, provavelmente constituíram o principal fator para este resultado.

Como o consumo de ração não variou entre os tratamentos, o crescente nível de inclusão de lisina na ração resultou em aumento $(\mathrm{P}<0,001)$ linear no consumo de lisina segundo a equação $\hat{Y}=0,343+42,30 \mathrm{X}$ $\left(r^{2}=0,99\right)$. O consumo de energia digestível, que correspondeu à média diária de $15.329 \mathrm{kcal}$, não variou $(\mathrm{P}>0,05)$ entre os tratamentos, o que está diretamente relacionado ao fato de as rações terem sido isoenergéticas.

Os resultados de desempenho das matrizes durante o período de lactação encontram-se na Tabela 4.

$\mathrm{O}$ peso das matrizes ao final da lactação não sofreu influência $(\mathrm{P}>0,05)$ do nível de lisina das rações, contrariando os relatos de Jones \& Stahly (1999b), que observaram relação positiva entre o nível de lisina das rações e o peso das matrizes ao desmame. Entretanto, estes autores utilizaram somente dois níveis de lisina, variando entre 0,34 e 1,20\%, enquanto, neste estudo, foram avaliados cinco níveis, com dife-

Tabela 2 - Valores médios das temperaturas registradas pelos termômetros de máxima (TMX), de mínima (TMN), de bulbo seco (TBS), de bulbo úmido (TBU) e de globo negro (TGN) e seus respectivos desvios-padrão medidos durante o período experimental na sala de maternidade

Table 2 - Values of average temperatures and the respective standard deviations of maximum (TMX) and minimum (TMN) thermometers, dry (TBS) and humid bulb (TBU) thermometers and average temperature of black globe thermometer (TGN), measured during the experimental period

\begin{tabular}{lccccc}
\hline $\begin{array}{l}\text { Horário } \\
\text { Time }\end{array}$ & \multicolumn{5}{c}{$\begin{array}{c}\text { Temperatura }\left({ }^{\circ} \mathrm{C}\right) \\
\text { Temperature }\left({ }^{\circ} \mathrm{C}\right)\end{array}$} \\
\cline { 2 - 6 } & TMX & TMN & TBS & TBU & TGN \\
\hline $8 \mathrm{~h}$ & $27,5 \pm 2,73$ & $19,0 \pm 2,12$ & $27,0 \pm 4,28$ & $21,3 \pm 3,46$ & $25,2 \pm 3,90$ \\
$12 \mathrm{~h}$ & $31,0 \pm 2,62$ & $20,3 \pm 2,54$ & $29,0 \pm 3,98$ & $23,0 \pm 3,02$ & $27,4 \pm 3,25$ \\
$17 \mathrm{~h}$ & $30,0 \pm 2,81$ & $18,0 \pm 2,65$ & $26,5 \pm 3,45$ & $22,0 \pm 3,64$ & $26,0 \pm 3,86$ \\
\hline
\end{tabular}


Tabela 3 - Consumo de ração, de lisina total e de energia digestível das fêmeas durante o período de lactação Table 3 - Feed intake and intakes total lysine and digestible energy of gilts during the lactation period

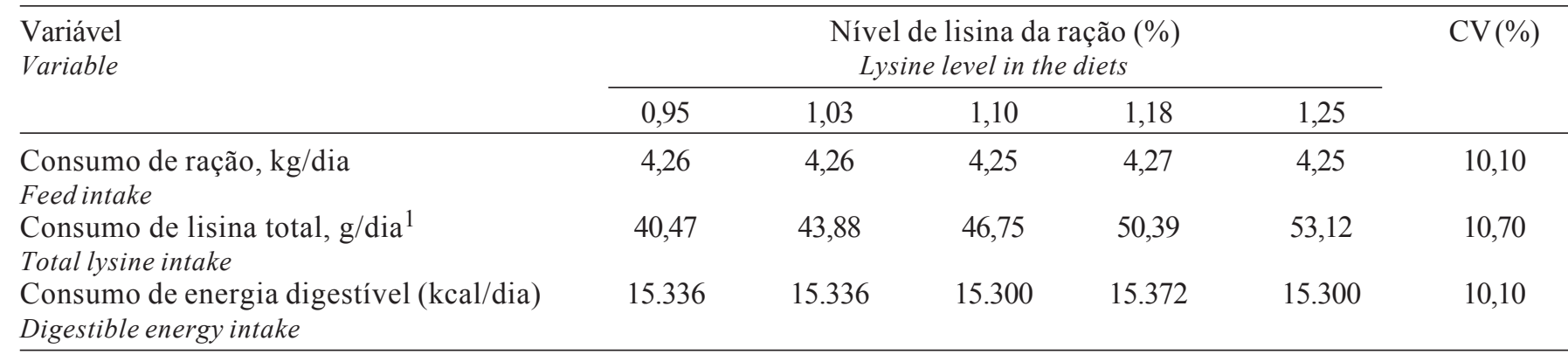

${ }^{1}$ Efeito linear $(P<0,05)$ (Linear effect, $\left.P<0.05\right)$.

Tabela 4 - Desempenho das fêmeas primíparas durante e após o período de lactação, de acordo com o nível de lisina da ração

Table 4 - Performance of primiparous sows during and after lactation period in response to lysine levels in the diet

\begin{tabular}{|c|c|c|c|c|c|c|}
\hline \multirow[t]{2}{*}{$\begin{array}{l}\text { Variável } \\
\text { Variable }\end{array}$} & \multicolumn{5}{|c|}{$\begin{array}{l}\text { Nível de lisina da ração (\%) } \\
\text { Lysine level in the diets }\end{array}$} & \multirow[t]{2}{*}{$\mathrm{CV}(\%)$} \\
\hline & 0,95 & 1,03 & 1,10 & 1,18 & 1,25 & \\
\hline Número de animais & 9 & 10 & 9 & 10 & 10 & \\
\hline Number of animals & & & & & & \\
\hline Peso da porca $(\mathrm{kg})$ & & & & & & \\
\hline \multicolumn{7}{|l|}{ Giltweight } \\
\hline Pós-parto & 217 & 208 & 203 & 212 & 211 & 10,5 \\
\hline Post-partum & & & & & & \\
\hline À desmama & 200 & 196 & 192 & 202 & 200 & 9,1 \\
\hline Atweaning & & & & & & \\
\hline Variação de peso $(\mathrm{kg})$ & -17 & -12 & -11 & -10 & -11 & 55,2 \\
\hline \multicolumn{7}{|l|}{ Weight change } \\
\hline Variação de peso relativa (\%) & 7,83 & 5,77 & 5,41 & 4,72 & 5,21 & 51,7 \\
\hline Relative weight variation & & & & & & \\
\hline Variação proteína corporal $(\%)^{1}$ & $-8,30$ & $-5,80$ & $-5,74$ & $-4,64$ & $-5,21$ & 44,2 \\
\hline \multicolumn{7}{|l|}{ Body protein variation } \\
\hline \multicolumn{7}{|l|}{ Espessura de toucinho (mm) } \\
\hline \multicolumn{7}{|l|}{ Backfat thickness } \\
\hline Pós-parto & 22,50 & 22,60 & 20,70 & 23,30 & 25,80 & 21,5 \\
\hline $\begin{array}{l}\text { Post-partum } \\
\text { À desmama }\end{array}$ & 2060 & 2080 & 1070 & 2160 & 2300 & 103 \\
\hline Atweaning & 20,60 & 20,80 & $19, / 0$ & 21,00 & 23,90 & \\
\hline Variação na ET (mm) & $-1,90$ & $-1,80$ & $-1,00$ & $-1,70$ & $-1,90$ & 132,8 \\
\hline Variation in $B T$ & & & & & & \\
\hline Produção de leite $(\mathrm{kg} / \mathrm{dia})^{2}$ & 6,70 & 6,03 & 6,42 & 6,34 & 6,70 & 15,7 \\
\hline Milkyield & & & & & & \\
\hline Produção de $\mathrm{N}$ no leite $(\mathrm{g} / \mathrm{dia})^{3}$ & 1035 & 1003 & 1005 & 1027 & 1084 & 18,8 \\
\hline Milk Nyield & & & & & & \\
\hline Intervalo desmama-estro, dias & 5,1 & 5,4 & 5,1 & 4,8 & 4,7 & 22,6 \\
\hline Weaning-estrus interval & & & & & & \\
\hline Número leitões nascidos no segundo parto & 10,8 & 10,0 & 11,4 & 12,1 & 12,0 & 21,2 \\
\hline
\end{tabular}

${ }^{1}$ Variação poteína corporal $(\mathrm{kg})=-2,3+(0,19 \times$ peso vivo, $\mathrm{kg})-[0,22 \mathrm{x}$ espessura de toucinho (P2; mm)]. Fonte: Whittemore \& Yang (1989).

1 Variation in body proteint $(\mathrm{kg})=-2.3+(0.19 \times$ live weight, $\mathrm{kg})-[0.22 \times$ backfat thickness $(P 2 ; \mathrm{mm})]$. Source: Whittemore \& Yang (1989).

${ }^{2}$ Produção de leite $(\mathrm{g} / \mathrm{dia})=7+[2,5 \mathrm{x}$ ganho de peso médio do leitão $(\mathrm{g})]+[80,2$ x peso inicial do leitão $(\mathrm{kg})]$ x número de leitões. Fonte: Noblet \& Etienne (1989).

${ }^{2}$ Milk yield $(\mathrm{g} /$ day $)=7+[2.5 X$ daily weight gain $(\mathrm{g})]+[80.2 \times$ born weight $(\mathrm{kg})] \times$ number of piglet. Source: Noblet \& Etienne (1989).

3 Produção de $\mathrm{N}$ no leite $(\mathrm{g} / \mathrm{leitão} / \mathrm{dia})=0,0257 \times$ ganho de peso do leitão $(\mathrm{g}) \times 0,42$.

${ }^{3}$ Milk $N$ yield (g/pig/day) $=0.0257 \times$ daily weight gain $(g) \times 0.42$. 
rença máxima de $0,30 \%$ entre os níveis extremos utilizados.

Durante o período lactacional, não se observou efeito das concentrações de lisina na ração $(\mathrm{P}>0,05)$ sobre a variação de peso das matrizes e sobre a variação da proteína corporal. Assim como neste trabalho, Knabe et al. (1996), Yang et al. (2000a) e Cota et al. (2003) também não observaram variação significativa no peso corporal das matrizes durante a lactação em função dos níveis de lisina na ração. Em contrapartida, estes resultados diferem dos obtidos por King \& Martin (1989), Richert et al. (1994), Yang et al. (2000a) e Mejia-Guadarrama et al. (2002), que verificaram maior perda de peso nas matrizes primíparas que receberam as rações com os mais baixos níveis de lisina avaliados.

As variações de resultados entre os trabalhos podem ser justificadas pelo fato de Yang et al. (2000a) e Mejia-Guadarrama et al. (2002) terem utilizados níveis de lisina $(0,40$ e $0,50 \%$, respectivamente) abaixo dos valores mínimos avaliados pelos demais autores. Embora, neste estudo, não se tenha observado diferença $(\mathrm{P}>0,05)$ na variação de peso das matrizes durante a lactação, verificou-se que aquelas que consumiram a ração contendo menor concentração de lisina total $(0,95 \%)$ perderam mais peso $(7,83 \%) \mathrm{e}$ proteína corporal $(8,30 \%)$ que aquelas que consumiram ração com $1,25 \%$ de lisina.

Os níveis de lisina não influenciaram $(\mathrm{P}>0,05)$ a variação da espessura de toucinho das fêmeas. Resultados semelhantes foram observados por King \& Martin (1989), Johnston et al. (1993), Richert et al. (1994), Sauber et al. (1998), Touchette et al. (1998), Jones \& Stahly (1999a), Yang et al. (2000b), Cota et al. (2003) e Mejia-Guadarrama et al. (2002). Considerando a variação do peso corporal das matrizes, podese inferir que a variação na espessura de toucinho foi um parâmetro sensível para avaliação da condição corporal desses animais. Este resultado contraria os relatos de Jones \& Stahly (1999a) e Cota et al. (2003) de que a espessura de toucinho não reflete a variação na condição corporal de fêmeas suínas primíparas.

Não foi verificado efeito $(\mathrm{P}>0,05)$ dos níveis de lisina da ração sobre a produção de leite e de nitrogênio no leite das matrizes. Confirmando esses resultados, Dourmad et al. (1998) também não verificaram efeito dos níveis de lisina sobre a produção de leite e de nitrogênio no leite de matrizes primíparas, mesmo com consumo de lisina de 27,59 a 38,63 g por dia.
Por outro lado, avaliando ração com baixo e alto nível de proteína para matrizes com diferentes condições corporais ao parto (magra ou gorda), Revell et al. (1998) verificaram que a produção e a concentração de proteína no leite foram menores nas matrizes que receberam a ração com baixo nível de lisina, independentemente da condição corporal dos animais ao parto. Da mesma forma, Jones \& Stahly (1999 b) verificaram menor produção de leite e de proteína no leite nas fêmeas suínas primíparas que consumiram $16,20 \mathrm{~g}$ de lisina por dia em relação às que consumiram $58,90 \mathrm{~g}$.

Esses resultados indicam que as fêmeas suínas são capazes de manter a produção do leite utilizandose uma progressiva mobilização de reservas corporais até determinado ponto, a partir do qual a mobilização de tecido não é mais suficiente para manter esta produção. Clowes et al. (2003) afirmaram que as matrizes são capazes de manter sua produção de leite utilizando de 9 a $12 \%$ da massa de proteína corporal e que demanda de mobilização de tecido acima desses valores resulta em diminuição da quantidade do leite produzido.

As características de desempenho reprodutivo subseqüente, como o intervalo desmama-estro (IDE) e o número de leitões nascidos no segundo parto, não foram influenciadas $(\mathrm{P}>0,05)$ pelos níveis de lisina da ração, o que corrobora as observações de Touchette et al. (1998). Entretanto, Jones \& Stahly (1999b) relataram aumento nos dias para o início do estro após a desmama em fêmeas que consumiram baixos níveis de lisina. Provavelmente, esse aumento do IDE tenha decorrido do consumo muito baixo de lisina (correspondente a $16,20 \mathrm{~g}$ ), o que ocasionou aumento de perda corporal das matrizes, comprometendo sua eficiência reprodutiva.

O IDE de 5,02 $\pm 1,16$ dias observado neste estudo foi semelhante ao de 5,10 dias encontrado por Cota et al. (2003), em estudos conduzidos para avaliação de níveis de lisina para marrãs em lactação, e encontrase dentro do intervalo de três a seis dias definido por Zak et al. (1997) como típico para matrizes primíparas com período de lactação de aproximadamente 20 dias.

Considerando o relato feito por Clowes et al. (2003), com base em dados de 16 experimentos, de que o aumento do intervalo desmama-estro, normalmente ocorre quando as fêmeas mobilizam mais que $16 \%$ de sua massa protéica, o fato de as matrizes terem perdido no máximo $8,30 \%$ de sua massa protéica 
corporal justifica a ausência de variação do IDE entre os tratamentos.

Embora não se tenha observado efeito $(\mathrm{P}>0,05)$ do consumo de lisina sobre o número de leitões nascidos no segundo parto, pode-se inferir que as fêmeas que consumiram a ração contendo $1,25 \%$ de lisina apresentaram aumento de 1,2 leitão no segundo parto, quando comparadas àquelas que consumiram ração com $0,95 \%$ de lisina total.

Os resultados de ganho de peso dos leitões e da leitegada durante o período de lactação encontram-se na Tabela 5 .

Não se observou variação $(\mathrm{P}>0,05)$ no número de leitões à desmama entre os tratamentos. Como adotou-se o critério de equalização de leitegada, esse resultado refletiu o baixo índice de mortalidade e/ou descarte de leitões ocorrido durante o período experimental. A relevância deste resultado está relacionada ao fato de que uma possível variação no tamanho da leitegada à desmama poderia influenciar a resposta de produção de leite das matrizes e, conseqüentemente, o ganho de peso dos leitões.
Com base na produção de leite, o NRC (1998) preconiza que as matrizes em lactação necessitam de um adicional de 4,70 $\mathrm{g}$ de lisina digestível verdadeira por dia para cada leitão a mais na leitegada, enquanto Kim et al. (1999), considerando o crescimento das glândulas mamárias, concluíram que exigem um adicional de $0,96 \mathrm{~g}$ de lisina por dia para cada leitão a mais em aleitamento. Resultados obtidos por Revell et al. (1998) confirmam que o número de leitões na leitegada influencia a produção de leite das fêmeas em lactação.

Não houve efeito $(\mathrm{P}>0,05)$ dos níveis de lisina sobre o ganho de peso médio diário e total dos leitões e da leitegada, embora o consumo de lisina tenha variado de 40,47 a 53,12 g/dia. De forma semelhante, Dourmad et al. (1998), Mejia-Guadarrama et al. (2002), Cota et al. (2003) e Clowes et al. (2003) não verificaram efeito da variação do consumo de lisina em valores correspondentes, ou mesmo em consumo inferior (20,40 g) ao observado neste estudo, sobre o ganho de peso dos leitões e/ou das leitegadas durante o período de aleitamento.

Tabela 5 - Desempenho da leitegada equalizada, durante a lactação, de acordo com o nível de lisina da ração Table 5 - Performance of equalized litter during the lactation phase according to the lysine level in the diet

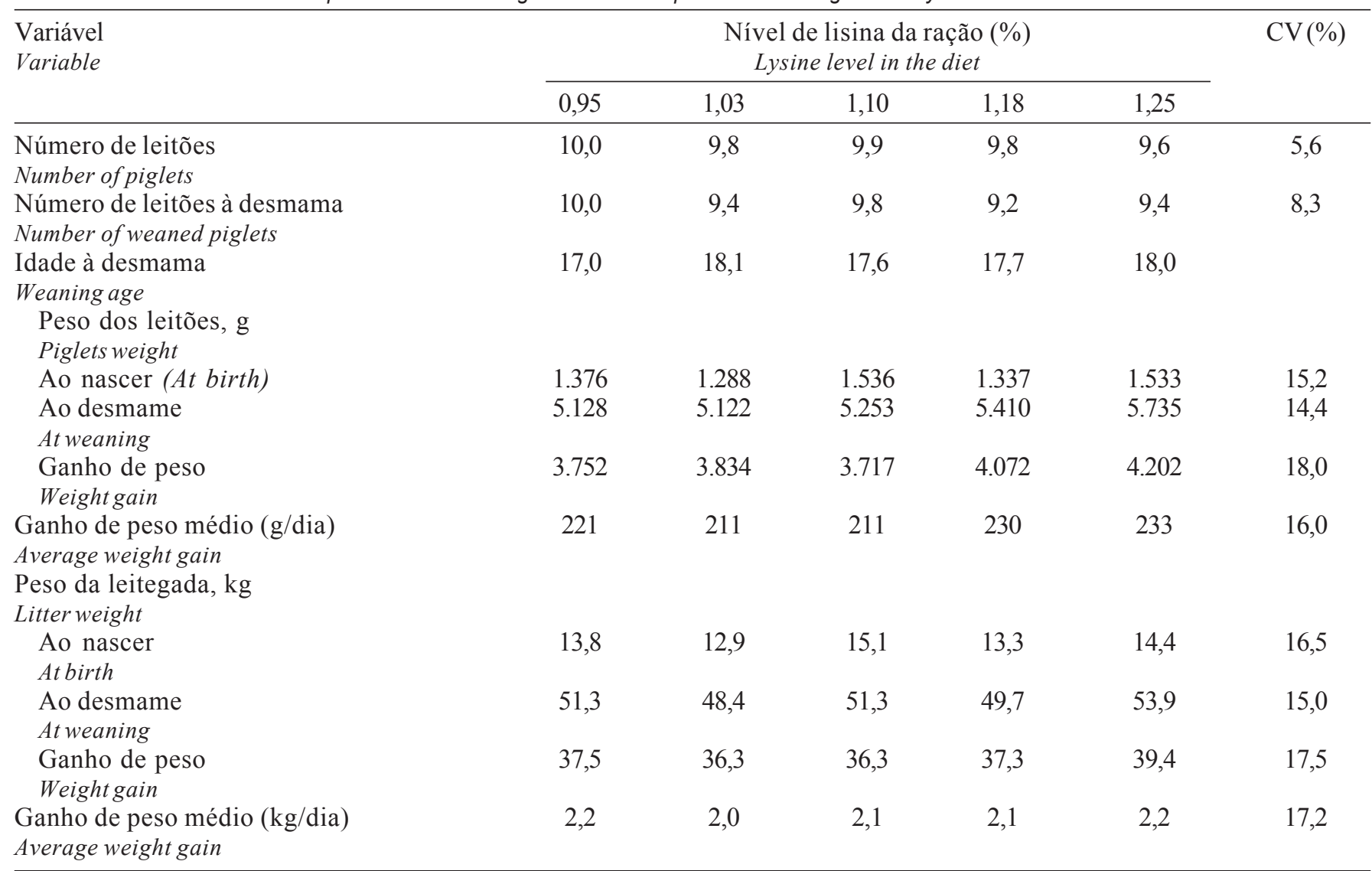


Em contrapartida, Jones \& Stahly (1999a) e Yang et al. (2000b), avaliando níveis de lisina para fêmeas suínas primíparas, em que o consumo diário de lisina correspondeu a 16,20 e 58,90 g e a 16,00; 36,00 e 56,00 g, respectivamente, verificaram que as leitegadas das matrizes que consumiram 16,20 e 16,00 g de lisina, respectivamente, apresentaram menor ganho de peso que as dos demais tratamentos.

Considerando os resultados obtidos por esses autores, pode-se inferir que as fêmeas suínas primíparas são capazes de manter o ganho de peso de suas leitegadas até a um limite mínimo de consumo de 20,70 g de lisina/dia.

Entretanto, embora não se tenha observado efeito de tratamento $(\mathrm{P}>0,05)$ sobre o ganho de peso dos leitões, houve uma diferença de $5 \%$ no ganho de peso médio diário entre os animais dos dois níveis extremos de lisina $(0,95$ e $1,25 \%)$ avaliados.

\section{Conclusões}

Matrizes suínas primíparas em lactação exigem $0,95 \%$ de lisina total, correspondente a um consumo de $40,47 \mathrm{~g} / \mathrm{dia}$.

\section{Literatura Citada}

CARTER, S.D.; HILL, G.M.; MAHAN, D.C. et al. Effects of dietary valine concentration on lactational performance of sows nursing large litters. Journal of Animal Science, v.78, p.2879-2884, 2000.

CLOWES, E.J.; AHERNE, F.X.; FOXCROFT, G.R. et al. Selective protein loss in lactating sows is associated with reduced litter growth and ovarian function. Journal of Animal Science, v.81, p.753-764, 2003.

COTA, T.S.; DONZELE, J.L.; OLIVEIRA, R.F.M. et al. Níveis de lisina em ração de lactação para fêmeas suínas primíparas. Revista Brasileira de Zootecnia, v.31, n.1, p.115-122, 2003.

DOURMAD, J.Y.; NOBLET, J.; ÉTIENE, M. Effect of protein and lysine supply on performance, nitrogen balance, and body composition changes of sows during lactation. Journal of Animal Science, v.76, p.542-550, 1998

JONES, D.B.; STAHLY, T.S. Impact of amino acid nutrition during lactation on luteinizing hormone secretion and return to estrus in primiparous sows. Journal of Animal Science, v.77, p.523-1531, 1999a.

JONES, D.B.; STAHLY, T.S. Impact of amino acid nutrition during lactation on body nutrient mobilization and milk nutrient output in primiparous sows. Journal of Animal Science, v.77, p.1513-1522, 1999b.

JOHNSTON, L.J.; PETTIGREW, J.E.; RUST, J.W. Response of maternal-line sows to dietary protein concentration during lactation. Journal of Animal Science, v.71, p.21522156, 1993.
KIM, S.W.; OSAKA, I.; HURLEY, W.L. et al. Mammary gland growth as influenced by litter size in lactating sows: impact on lysine requirement. Journal of Animal Science, v.77, p.3316-3321, 1999.

KING, R.H.; DUNKIN, A.C. The effect of nutrition on the reproductive performance of first-litter sows. Animal Production, v.43, p.319-325, 1986.

KING, R.H.; MARTIN, G.B. Relationship between protein intake during lactation, LH levels and oestrous activity in first-litter sow. Animal Reproduction Science, v.19, p.283-292, 1989.

KNABE, D.A.; BRENDEMUHL, J.H.; CHIBA, L.I. et al. Supplemental lysine for sows nursing large litters. Journal of Animal Science, v.74, p.1635-1640, 1996.

MEJIA-GUADARRAMA, C.A.; PASQUIER, A.; DOURMAD, A. et al. Protein (lysine) restriction in primiparous lactating sows: on metabolic state, somatotropic axis, and reproductive performance after weaning. Journal of Animal Science, v.80, p.3286-3300, 2002.

NÄÄS, I.A. Influência do ambiente na resposta reprodutiva de fêmeas. In: SIMPÓSIO INTERNACIONAL DE REPRODUÇÃO E INSEMINAÇÃO ARTIFICIAL EM SUÍNOS, 7., 2000, Foz do Iguaçu. Anais... Foz do Iguaçu, 2000. p. 253-262.

NATIONAL RESEARCH COUNCIL. - NRC. Nutrient requirements of swine. 10.ed. Washington, D.C.: National Academic Science, Committee Animal Nutrition. Subcommittee of Swine Nutrition, 1998. 189p.

NOBLET, J.; ETIENNE, M. Estimation of sow milk nutrient output. Journal of Animal Science, v.67, p.3352-3359, 1989.

RICHERT, B.T.; GOODBAND, R.D.; TOKACH, M.D. et al. The effect of lysine and valine fed during lactation on sow and litter lactation performance. Swine Day, p.19-23, 1994

REVELL, D.K.; WILLIAMS, I.H.; MULLAN, B.P. et al. Body composition at farrowing and nutrition during lactation affect the performance of primiparous sows: II. Milk composition, milk yield, and pig growth. Journal of Animal Science, v.76, p.1738-1743, 1998 .

ROSTAGNO, H.S.; ALBINO, L.F.T.; DONZELE, J.L. et al. Composição de alimentos e exigências nutricionais de aves e suínos: Tabelas Brasileiras. Viçosa, MG: Universidade Federal de Viçosa, 2000. 141p.

SAUBER, T.E.; STAHLY, T.S.; WILLIAMS, N.H. et al. Effect of lean growth genotype and dietary amino acid regime on lactational performance of sows. Journal of Animal Science, v.76, p.1098-1111, 1998.

TOKACH, M.D.; PETTIGREW, J.E.; DIAL, G.D. et al. Characterization of luteinizing hormone secretion in the primiparous, lactating sow: relationship to blood metabolites and return-to-estrus interval. Journal of Animal Science, v.70, p.2195-2201, 1992

TOUCHETTE, K.J.; ALLEE, G.L.; NEWCOMB, M.D. et al. The lysine requirement of lactating primiparous sows. Journal of Animal Science, v.76, p.1091-1097, 1998.

UNIVERSIDADE FEDERAL DE VIÇOSA-UFV. SAEG - Sistema de Análises Estatísticas e Genéticas. Versão 7.1.Viçosa, MG: 1997. 150p. (Manual do usuário).

YANG, H.; PETTIGREW, J.E.; JOHNSTON, L.J. et al. Lactational and subsequent reproductive responses of lactating sows to dietary lysine (protein) concentration. Journal of Animal Science, v.78, p.348-357, 2000a. 
YANG, H.; PETTIGREW, J.E.; JOHNSTON, L.J. et al. Effects of dietary lysine intake during lactation on blood metabolites hormones, and reproductive performance in primiparous sows. Journal of Animal Science, v.78, p.1001-1009, 2000b.

WHiTTEMORE, C.T.; YANG, H. Physical and chemical composition of the body of breeding sows with differing body subcutaneous fat depth at parturition, differing nutrition during lactation and differing litter size. Animal Production, v.48, p.203-212, 1989.

WILSON, M.E.; STEIN, H.; TROTTIER, N.L. et al. Effect of lysine intake on reproduction performance in first parity sows. Journal of Animal Science, v.74, p.63, 1996. Suppl.1.
ZAK, L.J.; COSGROVE, J.R.; AHERNE, F.X. et al. Pattern of feed intake and associated metabolic and endocrine changes differentially affect postweaning fertility in primiparous lactating sows. Journal of Animal Science, v.75, p.208216, 1997.

Recebido em: 03/10/04

Aceito em: 14/06/05 